\title{
THE SCIENTIFIC REVOLUTION OF THE 17TH CENTURY. THE ASPECTS CONNECTED TO PHYSICS AND ASTRONOMY: AN EDUCATIONAL ITINERARY IN SEVEN LESSONS
}

Paolo Bussotti

Commission for the Publication of the National Edition of Federigo Enriques's Works, Italy E-mail: paolobussotti66@gmail.com

\section{Introduction}

In the period 2012-2013 I got the qualification (abilitazione) to teach history and philosophy in the Italian high schools. The course I followed was called TFA (Tirocinio Formativo Attivo, Active Formative Training). The final examination was constituted by various proofs. Two of them were the written presentations of one educational itinerary in history and one in philosophy. Both of them had to be structured in a series of interconnected lessons. In this editorial I will expose, with some minor modifications, the translation of the educational itinerary I prepared for philosophy. It concerns the scientific revolution of the 17th century. The interest of this itinerary is not limited to the schools in which philosophy is taught, but it can also provide ideas useful in a course of physics at the high school or of history and philosophy of science at the university. What follows is divided into two parts: 1) a general presentation of the aims and methods followed in the lessons; 2) the lessons of the educational itinerary. In my training in philosophy - developed in September and October 2013 in an Italian scientific high school - I presented the following lessons concerning the scientific revolution.

\section{Presentation of the Educational Itinerary}

The educational itinerary I am proposing is divided into seven lessons and concerns the scientific revolution of the 17th century. In particular the aspects connected to the birth of modern physics and to the structure held by the Copernican theory in the 17th century will be dealt with. In consequence of Kepler's work, such a structure is considerably different from the original one presented by Copernicus in his De revolutionibus orbium coelestium (1543). Many scientists gave remarkable contributions to the so called scientific revolution, but we will focus on four of them: Galilei, Kepler, Descartes and Newton. The initial and final limits of the educational itinerary are respectively represented by the publication of Kepler's Mysterium Cosmographicum (1596) and Newton's Philosophiae Naturalis Principia Mathematica (1687). The new astronomy and the new physics are born in this lapse of time.

The reasons why I chose this subject are:

1) the conceptual and social importance of the scientific revolution;

2) physics and astronomy were the first two sciences which were framed with modern criteria, namely with criteria and methods that, mutatis mutandis, are valid nowadays, too;

3) physics and astronomy became strictly connected; 
Paolo Bussotti. The Scientific Revolution of the 17th Century. The Aspects Connected to Physics and Astronomy: an Educational Itinerary in Seven Lessons

OF EDU

PROBLEMS

IN THE $21^{\text {st }}$ CENTURY

Volume 58,2014

4) the interaction of the mathematical aspect with the empirical one (experimental for physics, observative for astronomy) is particularly remarkable in these two sciences and can be explained in an educational itinerary.

The four characteristics of the scientific revolution explained in the handbooks for history and philosophy and that have become communis opinio are:

1) the relations between the facts of the physical world are determined by the causeeffect link. These relations can be expressed in mathematical terms. From an educational point of view, the distinction between the concept of causation expressed by the four Aristotelian causes and that connoting modern science has to be stressed;

2) the mathematization of the physical world and the concept of law connected to the intersubjective value of the mathematical language. This means that science has a democratic character because mathematics should supply a universal language through which all men can communicate.

3) role of the experiments and so called experimental method. As to this, a series of experiments carried out by Galilei at the beginning of the 17 th century will be briefly reported. These experiments drove Galileo from the wrong idea that, in the uniformly accelerated motion, the velocities are as the spaces to the correct conclusion that the velocities are as the times (see lesson 2).

4) the historical, social and political circumstances that favoured the scientific revolution. In this context the relations science-technique will be addressed as well as the improved control of space and time achieved in that period. A trace of this requirement is also present in Newton's Principia (Book I, second corollary to the axioms or laws of movement).

Some critical considerations are necessary. During the proposed lessons, two problems will be in particular dealt with:

1) relation between experimental method and mathematics. The experimental aspect of science at the beginning of the 17th century was not methodical: the experiments were fundamental but they were not carried out in a uniform and methodic manner. It could happen that a scientist got some vague ideas how some physical laws could be expressed and tried to verify them through experiments; or, on the contrary, the laws were drawn from some experiments and data without having an a priori idea what the mathematical expression of such laws could be. Often the functioning itself of the instruments with which experiments or observations were carried out was not supported by an adequate theory. As to this, some passages of Feyeabend's book Against Method will be suggested to the pupils (see lesson 2). It will be shown how, at the end of the 17th century, the experimental methods became more codified, even if the creativeness of the experimenter will be always important.

2) Critics of the concept of experience: not all of the Aristotelians were unskilled scientists. Many of them were interested in the results of experience. For, Aristotelian philosophy has often been defined - I think rightly - as the ,philosophy of the common sense“. For, the idea that the Earth rotate around the Sun and the faith in the observations made by the spy-glass (Galilei, Sidereus Nuncius) - according to which the Moon has a rough surface - rather than in those carried out with the naked eye, according to which Moon's surface is almost perfectly smooth, prove that the concept of experience is relative to a whole system of convictions. It is not an absolute concept. Let us think that the Aristotelians believed neither in Earth's rotation nor in the observations with the spy-glass. These considerations can be instructive for the pupils as far as they show that no concept can be given for granted in a too simple manner.

With regard to physics and astronomy, the initial point will be Kepler's work. The main results obtained in Mysterium Cosmographicum and, above all, Astronomia Nova (1609) will be examined. In Astronomia Nova Kepler exposed the first two of his three planetary laws. His analysis starts from Thycho Brahe's observations: Kepler pointed out that no one of the classical astronomical models, based on the circular motion, can supply both Mars' latitude and longitude with a margin of error coherent with Brahe's observations. He elaborated various models in which the planetary motion is still circular. However, none of them worked without 
postulating hypothetical motions of some particular points, motions which were not plausible from a physical point of view. From here the long intellectual itinerary which brought Kepler to the elliptical orbits began. This is instructive for the students because: 1) it shows how theory and observations are tied in astronomy. For, without the precise Brahe's observations, the acceptable margin of error was so wide that the best Ptolemaic models or the Copernican one, in the version given by Copernicus based on circular orbits, could work with few modifications; 2) Kepler spoke of the physical improbability as to the motion of certain immaterial points (as the punctum equans). This means Kepler wanted to make the Copernican system the very physical system of the world, not only a kinematical model that „saves the phenomena“ (to tell à la Duhem), that is a mere mathematical hypothesis. In the Mysterium Cosmographicum Kepler had already written he aimed to find the physical and metaphysical basis of the Copernican system. The explanations of Kepler's ideas will drive the teacher to analyse the difference between a kinematical and a dynamical explanation of the phenomena, the role of the concept of force in Kepler, the value, which is also metaphysical, of Kepler's theory (Mysterium Cosmographicum). A comparison will be set between Kepler's and Galilei's (Sidereus Nuncius, Discorso sopra i due massimi sistemi del mondo) contributions to astronomy and between the personalities and mentalities of these two great scientists. They look so different because of a different temperament and cultural legacy (lessons 4 and 5).

With regard to physics, mainly the basic-principles will be pointed out. The itinerary will begin with the concept of inertia refusing the idea that the inertia principle was formulated by Galileo in the Dialogo (1632) or by Descartes in the Principia philosophiae (1644). The first clear formulation of this principle was provided only by Newton in his Principia (first law of the movement). It will be explained that Galilei and Descartes formulated propositions similar to the inertia principle. However, this principle cannot be clear without a precise notion of mass and of force as a vector whose verse and direction is that of the acceleration and whose intensity is given by the product of mass times acceleration. This fundamental step exists neither in Galilei nor in Descartes, but in Newton (lesson 7).

The most relevant contributions given by Galilei to physics (uniformly accelerated motion, motion of the pendulum, resistance of the materials) will be highlighted as well as the complex relation existing in Galilei's physics between the mathematical and experimental aspect with the role attributed by Galilei to mathematics. As to Descartes and his physics, the methods he used in the Principia philosophiae and in the two essays La Dioptrique and Les Météores will be pointed out. This method is different: the exposition of the Principia is, basically, aprioristic (Bussotti-Pisano, 2013). In the Principia, Descartes defended his collision rules (which are wrong apart from the first one) and denied the most evident experiences, whereas in the two essays an experimental-mathematical approach subsists. The reasons that induced Descartes to use such different styles and methods will be remarked. These reasons are not only scientific, but are also tied to the particular social and cultural situation in which Descartes lived (lesson 6). Newton will conclude the proposed educational itinerary. It is necessary to point out that, for the first time in history, Newton constructed a very physical model of the universe, based on laws whose principles are clearly highlighted (lesson 7).

Finally, the teacher could deal with a complex problem: what are the relations between science and society? Is the social structure to determine the way in which science is carried out? Can the science induce social modifications? Is there a cause-effect link or rather is there a reciprocal influence that, in the 17 th century, was one of the fundamental events from which the "modern man" is born? In this case the teacher should not give a definitive answer - also considering that maybe such an answer does not exist - but should induce a discussion among the students by providing some indications and elements useful in the discussion. 
OF EDU

PROBLEMS

IN THE $21^{\text {st }}$ CENTURY

Volume 58, 2014

\section{The Lessons}

Lesson 1 (two hours). At the beginning of the lesson, the essential characters of the scientific revolution will be introduced. In particular the role of mathematics inside the complex evolution of science will be pointed out. For this purpose, the famous passage written by Galileo in the Saggiatore (see Appendix, reading 1) will be commented and the intersubjective value of the mathematical language will be discussed. Kepler and Galilei claimed to be Pythagoreans and to refer to Plato for some aspects of their thought. It is necessary to analyse why they felt the need to refer to two ancient schools as the Pythagorean and the Platonic ones. The link between this reference and the value ascribed to mathematics by the two great scientists will be remarked. The problem of causation is strictly connected to this picture. In this regard, the doctrine of the four causes, expressed by Aristotle in his Physics, will be recalled, stressing that the new science was interested in that cause Aristotle called efficient. The connection between the mechanistic conception - to which many scientists in the course of the 17th century adhered -, the role of mathematics in science and the analysis of the causes exclusively in terms of efficient cause will be examined. It is, however, appropriate to underline that not all the great scientists were mechanistic. Kepler, for example, was not. The influence of the Renaissance philosophy on some of the protagonists of the scientific revolution will be also considered.

Lesson 2 (one hour). This lesson is dedicated to the experimental method. The meaning of this location will be explained. It is important to specify that experiments had a fundamental role in the initial phases of the scientific revolution, nevertheless it was not yet possible to speak of an experimental method. This expression can be used in a correct manner - and with some limitations - only starting from the second half of the 17th century. As to this, the discoveries of Galilei on the accelerated motion will be analysed, which were achieved through not-methodic procedures. The distinction between experiment and mental experiment will be clarified. As to this problem, the famous experiment of Newton's bucket will be presented to the pupils. Newton tried to justify the existence of absolute space by means of this experiment. After the concept of experiment, the one of experience will be analysed: this concept is not simple, at all. A critical analysis of experience is necessary in order to understand the different conceptions of the universe because the notion of experience is not absolute, but connected to a whole system of convictions and ideas. Galilei's use the spy-glass (Sidereus Nuncius) will drive the pupils inside this problem. The teacher will point out the reasons of Kepler's surprise when he saw that the spy-glass worked in the observation of the sky (Dissertatio cum Nuncio Sidereo). The critical remarks of the Aristotelians against the use of the spy-glass will be stressed, pointing out that these remarks were not always illogical. Some passages of Paul Feyerabend's book Against Method will be exposed to clarify the situation (see appendix, reading 3).

Lesson 3 (one hour). This lesson is conceived as a discussion with the pupils concerning the complex relations science-society: the socio-economical changes in Europe during the end of the 16th and the whole 17th century will be faced as well as a possible link between them and the scientific revolution. The thesis according to which economy and society determine, in substance, the evolution of science will be discussed together with the opposite one that science - thanks to the technical improvements in the construction of ships and machines, in agricultural methods and, in general, in the control of space and time (let us think of the improvements of the clocks) - influences the evolution of society. In this lesson the connection science-technology will be addressed, too.

Lesson 4 (two hours). Lesson dedicated to Kepler's astronomy. The bases of the Copernican system will be explained: 1) heliocentric system; 2) the system is still kinematical, not yet dynamical. The means used by Ptolemy (epicycles or circular eccentric orbits) are used by Copernicus, too. For the so called first inequality (the motion of the planets does not appear circular and uniform) Copernicus' models are easier than Ptolemy's, but for the second inequality (retrograde motion of the planets) Copernicus' devices are still more complicated than Ptolemy's. Kepler's idea to supply physical causes for planetary motions will be clarified. Com- 
plex Kepler's itinerary that brought the German scientist, in his Astronomia Nova, to discover the area laws and the ellipticity of the orbits will be briefly exposed.

Thanks to the accurate Brahe's observations, Kepler could exploit more reliable and precise data than those available to his predecessors. This fact helped him in the research of more refined planetary models because, in consequence of better observations, the admissible margin of error was dimished. These remarks will introduce into two subjects: 1) what is the role of observation in astronomy? 2) what is the role of error in science? The lesson will be concluded by some considerations whether Kepler really obtained the aim to provide a physical model of the solar system.

Lesson 5 (one hour). Lesson dedicated to Galilei as an astronomer, beginning with the contributions he gave in the Sidereus Nuncius. It will be pointed out that Galilei mines the philosophical presuppositions of the Ptolemaic-Aristotelian doctrine: 1) perfection of the superlunar world: Galilei shows, by means of the spy-glass, that the moon is rough and similar to the Earth. It is not composed of ethereal matter, as the Aristotelians believed. The imagines of the moon sketched by Galilei will be shown (see appendix, figure 1);2) most part of the so called nebulas are set of stars - similar to our sun - which compose our galaxy, the Milky Way; 3 ) the Earth is not the only celestial body around which other bodies rotate. Discovery of Jupiter's satellites. The analysis of Sidereus Nuncius will introduce into an interesting discussion: Galilei used the spy-glass. A convincing theory of refraction did not exist. Kepler, who knew optics far better than Galilei, did not build a telescope because of this lack. Galilei did and succeeded. Thus, which are the relations science-technique? Is the support of a theory always necessary to have a technique which works?

Some arguments ideated by Galilei in favour of the diurnal motion of the Earth will also be faced. A brief discussion with the pupils if these arguments are convincing will be carried out.

Lesson 6 (two hours). Lesson dedicated to the birth of modern physics:

1) Galilei's contributions in Discorsi e dimostrazioni intorno a due nuove scienze: uniformly accelerated motion, motion of the pendulum, resistance of the materials. Discussion how Galilei treated inertia principle; his conception of gravity. Given the importance of the problem, it is necessary to underline it was not yet clear that every cause inducing a modification in a motion (this cause will be called force by Newton) produces accelerations, not velocities. Only with Newton this will be understood.

2) Descartes' physics. Short account of the system proposed in his Principia philosophiae. Mechanism and inertia principle. Descartes' idea that experiment has a secondary role in comparison to theory (see Appendix, reading 2 concerning the collision). The essays La Dioptrique and Les Météores where in fact the experiments have a fundamental role. The difference between the Descartes which speaks of science and the Descsrtes who does science will be stressed. Descartes as an emblematic figure of the 17th century, a problematic epoch, that saw the affirmation of science, but in which the social role of the scientists was still ambiguous. A strong ecclesiastic censorship still existed. More in general the figure of the scientist was still ambiguous for the power holders: scientist as a potential subverter of the society (and because of this, dangerous) or as a person whose work can be controlled and directed? This question can favour an interesting discussion to develop together with the class.

Lesson 7 (one hour). Newton as the figure who concludes the scientific revolution: full comprehension of the basic principles of his physics: 1) inertia principle; 2) concept of force; 3 ) action and reaction principle. The relation between physics and mathematics in the Principia will be outlined as well as the new meaning of the concept of a physical system in Newton who successfully unified celestial and terrestrial physics. In particular the fact that gravity is the force responsible for the fall of the bodies on the Earth and for the rotation of the planets around the sun will be highlighted. Together with the pupils two questions will be posed and discussed: 1) is it possible to speak, after Newton, of scientific evolution rather than revolution? How did the social role of the scientist change in the brief period that separates Descartes from Newton? 
Paolo Bussotti. The Scientific Revolution of the 17th Century. The Aspects Connected to Physics and Astronomy: an Educational Itinerary in Seven Lessons

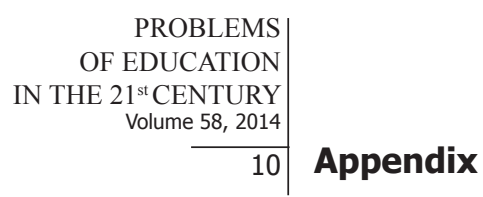

Reading 1: Galilei and the use of mathematics in physics.

What Galilei wrote in Il Saggiatore (The Assayer) is clear. It is only necessary to remind the reader that the word filosofia (philosophy) used by Galilei is equivalent to our physics.

Philosophy is written in this grand book, the universe, which stands continually open to our gaze. But the book cannot be understood unless one first learns to comprehend the language and read the letters in which it is composed. It is written in the language of mathematics, and its characters are triangles, circles, and other geometric figures without which it is humanly impossible to understand a single word of it; without these, one wanders about in a dark labyrinth. (Translation by Stillman Drake drawn from The Assayer, available on the Internet: http:// jraissati.com/PHIL201/Galileo_1623_TheAssayer.pdf, p. 4).

Reading 2: Descartes and the relation between theory and experience in the Principia Philosophiae.

Descartes, in the Principia Philosophiae analysed seven rules relative to the bodies collisions. All these rules are wrong, apart from the first one. Here I refer the first half of the seventh rule (Principia, second part, paragraph 52), which is evidently contrary to every experience, plus the final Descartes' sentence. Nevertheless, Descartes concluded such rules and their consequences are certain and they do not need empirical proves.

\section{The seventh rule.}

When two perfectly hard bodies, $x$ and $y$, with $x$ smaller than $y$, travelling in the same direction along the same straight line, $x$ moving faster than $y$, so that they collide when $x$ catches up with $y$, there are three different upshots that such a collision might have, depending on whether the amount by which $x$ 's speed exceeds $y$ 's speed is

(1) greater than,

(2) less than, or

(3) exactly the same as

the amount by which $y$ 's size exceeds $x$ 's. In case (1), $x$ will transfer to $y$ as much of its speed as is needed for them then to move at the same speed in the same direction. In case (2) $x$ will be driven back in the reverse of its previous direction, and will retain all its motion. In case (3), $x$ must transfer some of its motion to $y$ and bounce back with the rest. [...]

These matters don't need proof because they are self-evident.

(Translation drawn from the sitehttp://www.ahshistory.com/wp-content/uploads/2012/07/ descprin.pdf. A wide, even if not complete, translation into English of Descartes' Principia is available at this site, p. 37).

Reading 3: Feyerabend's arguments in favour of the idea that no theoretical certainty existed in support of Galilei's spy-glass functioning. Galilei, by resorting to the telescope, introduces, as a matter of fact, a new conception of experience. The summary of the chapters 8 , 9, 10 drawn from the third edition of Against Method (1993) are referred.

Chapter 8: In addition to natural interpretations, Galileo also changes sensations that seem to endanger Copernicus. He admits that there are such sensations, he praises Copernicus for having disregarded them, he claims to have removed them with the help of the telescope. However, he offers no theoretical reasons why the telescope should be expected to give a true picture of the sky (Feyerabend, 1975, 1993, p. 6). 
Paolo Bussotti. The Scientific Revolution of the 17th Century. The Aspects Connected to Physics and Astronomy: an Educational Itinerary in Seven Lessons

Chapter 9: Nor does the initial experience with the telescope provide such reason. The first telescopic observations of the sky are indistinct, indeterminatem contradictory and in conflict with what everyone can see with his unaided eyes. And, the only theory that could have helped to separate telescopic illusions from veridical phenomena was refused by simple tests. (Ivi, p. 6)

Chapter 10: On the other hand, there are some telescopic phenomena which are plainly Copernican. Galileo introduces these phenomena as independent evidence for Copernicus while the situation is rather that one refuted view - Copernicanism - has a certain similarity with phenomena emerging from another refuted view - the idea that telescopic phenomena are faithful images of the sky. (Ivi, pp. 6-7).

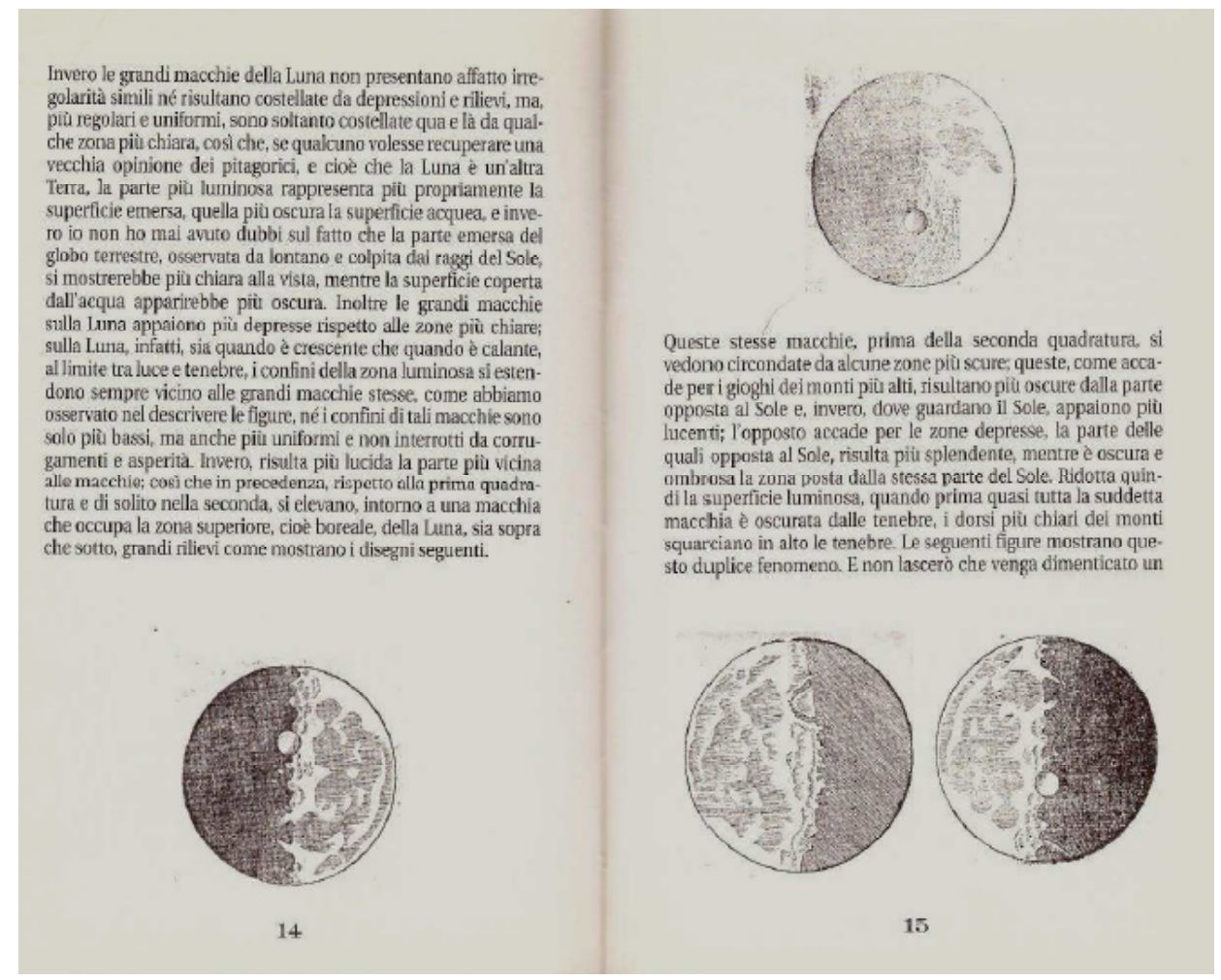

Drawn from Galilei, Sidereus Nuncius, 1610, 2001, pp. 14-15

Figure 1: The Moon, as it was represented by Galilei in the Sidereus Nuncius.

\section{References}

Bussotti, P. - Pisano, R. (2013). On the Conceptual and Civilization Frames in René Descartes' Physical Works. Advances in Historical Studies, 2, 3, 106-125.

Descartes, R. (1897-1913). OEuvres de Descartes. 12 vols, Adams C, Tannery P (eds). Paris.

Descartes, R. (1637). La Dioptrique. In OEuvres de Descartes, VI, 79-228.

Descartes, R. (1637). Les Météores. In OEuvres de Descartes, VI, 230-366.

Descartes, R. (1644). Principia Philosophiae. In OEuvres de Descartes, VIII.

Feyerabend, P. (1975, 1993). Against Method. London-New York: Verso.

Galilei, G. (1890-1909). Edizione Nazionale delle opere di Galileo Galilei. 20 volume, A. Favaro (Ed). Firenze: Barbera (reprint 1929-1939).

Galilei, G. (1610, 2001). Sidereus Nuncius. Translated from Latin into Italian and commented by P. Bussotti. Pisa: Pacini. See also Edizione Nazionale, III, first part. 
Paolo Bussotti. The Scientific Revolution of the 17th Century. The Aspects Connected to Physics and Astronomy: an Educational Itinerary in Seven Lessons

PROBLEMS

OF EDUCATION

IN THE $21^{\text {st }}$ CENTURY

Volume 58, 2014

Galilei, G. (1623). Il Saggiatore. In Edizione Nazionale, VI.

Galilei, G. (1632). Dialogo sopra i due massimi sistemi del mondo. In Edizione Nazionale, VII.

Galilei, G. (1638). Discorsi e dimostrazioni matematiche intorno a due nuove scienze. In Edizione Nazionale, VIII.

Kepler, J. (1937-2009). KGW, Kepler Gesammelte Werke, van Dyck, W.-Caspar M. (Eds). Deutsche Forschungsgemeineschaft and Bayerische Akademie der Wissenschaften. München: C. H. Beck'sche Verlagsbuchandlung.

Kepler, J. (1596). Prodromus dissertationum cosmographicum, continens Mysterium Cosmographicum [...]. In KGW, I.

Kepler, J. (1609). Astronomia Nova AITIOАОГЕТО $\Sigma$ seu phisica coelestis tradita de commentariis de motibus stellae Martis ex observationibus G. V. Tychonis Brahe. In KGW, III.

Kepler, J. (1610). Dissertatio cum Nuncio Sidereo. In KGW, IV, 281-311.

Newton, I. (1687, 1713, 1726, 1999). Philosphiae Naturalis Mathematica Principia, translated by B. Cohen and A. Whitman as The Principia: Mathematical Principles of Natural Philosophy. Berkeley: University of California Press.

Received: March 14, 2014

Accepted: March 26, 2014

Paolo Bussotti

PhD., Editor, Commission for the Publication of the National Edition of Federigo Enriques's Works, Via Paolo Lilla, 66, Livorno, 57122 Italy.

E-mail: paolo.bussotti@alice.it 